\title{
Primary hyperparathyroidism unmasked by donor nephrectomy
}

\author{
M. J. HOLLANDS \\ F.R.C.S.
}

\author{
GORDON WILLIAMS \\ F.R.C.S.
}

Urology and Transplant Unit, Department of Surgery, Hammersmith Hospital and Royal Postgraduate Medical School, London W12 OHS

\begin{abstract}
Summary
A patient who was normocalcaemic before donation of a kidney to her son developed hypercalcaemia in the immediate postoperative period, which was subsequently found to be due to a parathyroid adenoma. It is assumed that the hypercalcaemia was unmasked by the reduction in glomerular filtration rate following the nephrectomy.
\end{abstract}

KEY WORDS: hypercalcaemia, parathyroid adenoma, glomerular filtration rate, nephrectomy.

\section{Case report}

A 43-year-old woman was investigated as a potential kidney donor for her son. She was asymptomatic and physical examination revealed no abnormality. Routine pre-operative investigations showed serum protein $70 \mathrm{~g} /$ litre, albumin $42 \mathrm{~g} /$ litre, calcium $2 \cdot \mathrm{g}$ $\mathrm{mmol} /$ litre, inorganic phosphate $0.87 \mathrm{mmol} /$ litfe, alkaline phosphatase 85 i.u./litre, glomerular filtration rate (GFR) $90 \mathrm{ml} / \mathrm{min}$ and $110 \mathrm{ml} / \mathrm{min}$. A le्git nephrectomy was performed in July 1981. On the third postoperative day, a routine multi-channel biochemical screen was performed and she was found to be hypercalcaemic and hypophosphataémic. These changes persisted (Fig. 1). The seruin parathyroid hormone level was inappropriate fogthe level of serum calcium at $0.53 \mu \mathrm{g} / \mathrm{litre}$. Seven wees? after the nephrectomy, she underwent a parath dectomy and at operation, 3 parathyroids identified. The upper 2 were confirmed histologicaly

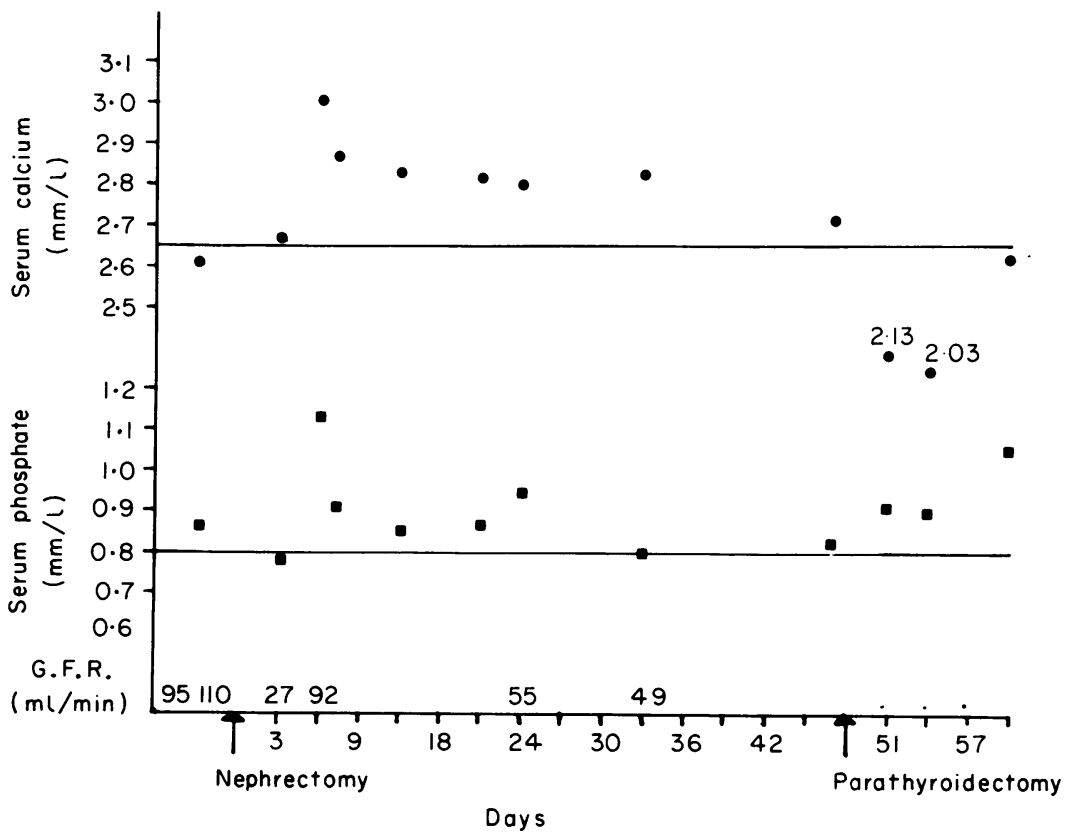

FIG. 1. Serum biochemistry and glomerular filtration rate (GFR) before and after nephrectomy and parathyroidectomy. 
to be normal, the lower left was enlarged measuring $12 \times 8 \times 5 \mathrm{~mm}$ and was confirmed histologically to be a parathyroid adenoma. This gland was removed. Postoperatively, her calcium fell to normal and has remained so.

\section{Discussion}

Hyperparathyroidism may be more common than previously suspected, with more cases being discovered through the increased utilisation of multi-channel biochemical screening. The apparent increase in prevalence of the disease has been paralleled by a change in the mode of clinical presentation. This report is, we believe, the first case of primary hyperparathyroidism to be unmasked by a nephrectomy.

Compensatory renal hypertrophy in the remaining kidney occurs rapidly after a nephrectomy. Krohn, Ogden and Holmes (1966) found that although there was a $33 \%$ increase in serum creatinine after a nephrectomy, the creatinine clearance rapidly in- creased to $70 \%$ of the pre-operative levels for both kidneys. James et al. (1981) showed that the GFR increased by $54 \%$ of the immediate postoperative level within a week of the nephrectomy. In our patient, the GFR was still only 50\% of the preoperative value one month after the nephrectomy which, we believe, was due to the hypercalcaemia and was also responsible for its unmasking. The glomerular filtration rate increased to $75 \%$ of the prenephrectomy level 2 weeks after the parathyroidectomy. In view of the case reported here, we suggest that serum calcium measurement should be undertaken pre- and postoperatively in all patients undergoing a nephrectomy.

\section{References}

James, A.N., Cranage, R.W., Fitzpatrick, J.M., Constable, A.R. \& WICKHAM, J.E. (1981) Serial changes in renal function and blood flow after nephrectomy. Urology, 18, 7.

KROHN, A.G., OGDEN, D.A. \& Holmes, J.H. (1966) Renal function in 29 healthy adults before and after nephrectomy. Journal of the American Medical Association, 196, 322.

(Accepted 1 July 1982) 